\title{
Home Advantage in Football: A Current Review of an Unsolved Puzzle
}

\author{
Richard Pollard*
}

Statistics Department, California Polytechnic State University, San Luis Obispo, U.S.A.

\begin{abstract}
The existence of home advantage in football is a well known and well documented fact. However the precise causes and the way in which they affect performance are still not clear. A comprehensive review is made of published research under the main hypothesized explanations for home advantage in football which are: crowd effects, travel effects, familiarity, referee bias, territoriality, specific tactics, rule factors and psychological factors. Their interactions, and other factors that need to be taken into account when investigating home advantage, are considered.
\end{abstract}

Home advantage in football has long been established as an important factor in determining the result of a game. Its existence is certain to affect the attitude of players, coaches, referees, fans and the media alike. Surprisingly, and despite over 25 years of research, the precise causes of home advantage and the way in which they operate are still not well understood. A review of the evidence for and against plausible explanations needs to be set against a background of the following basic facts. Home advantage has been in existence at least since the start of organized football at the end of the 19 th century. It is a worldwide phenomenon, but varies considerably from country to country. It has declined in the major leagues in Europe over the last 15 years. It tends to be greater in football than in other team sports.

The first report and quantitative description of home advantage in football was by Morris in 1981 [1]. This was soon followed by Dowie [2] and by Pollard [3] who gave a detailed quantitative description of home advantage in football and outlined the main hypothesized causes. This paper has been recently updated [4,5]. These explanations are now examined in the context of a comprehensive review of published research on home advantage as it relates specifically to football. The scope of this paper does not allow a detailed critical review of each publication, but should facilitate a literature review for any future research study on a specific aspect of football's home advantage.

\section{Crowd Effects}

This is the most obvious factor involved with home advantage and one that fans certainly believe to be dominant $[6,7]$. However the precise way in which crowd support has an effect has been difficult to pinpoint [2,3]. For example the relationship with crowd size is unclear and the advantage has been shown to operate even with very small crowds $[4,5,8]$. In addition to the size of the crowd, its density, intensity of support and proximity to the field of play are all factors that need to be considered $[9,10,11]$. Likewise, it is not known whether the primary effect of the crowd is to give an advantage to the home team or a disadvantage to the away team

*Address correspondence to this author at the 2401 Cloverfield Boulevard, Santa Monica, CA 90405, U.S.A.; Tel: +1 310 396-6715;

E-mail: richwpollard@yahoo.com and whether this is conveyed directly to the players or via referee decisions influenced by the crowd (see referee bias below). It is possible that the introduction of all-seater stadiums has modified the crowd effect.

\section{Travel Effects}

As with crowd support the evidence for a travel effect disadvantaging the away team is inconclusive. Distance traveled has been investigated within countries as well as internationally but with contradictory conclusions [2,3,12,13, $14,15,16]$. However, one consistent finding is that home advantage is reduced in local derbies where no travel is involved $[3,17,18]$.

\section{Familiarity}

When a team plays at home, it will be performing at a familiar stadium in familiar conditions amid familiar surroundings, all of which should provide an advantage. This concept has proved difficult to investigate, but some intriguing findings suggest that familiarity is a likely factor in home advantage. An advantage has been shown to exist on account of playing on artificial turf [19], on pitches with unusually large or small dimensions $[3,12]$ and with a make of football specific to the home team [20]. In addition there is some evidence that familiarity with local climatic conditions and with altitude has an effect favoring the home team $[16,18,21]$. Loss of familiarity has been suggested as a cause of the drop in home advantage in England and in Italy immediately after the long interruption of play due to World War II $[1,8]$. It also should apply in the same way when a team moves to a new stadium.

\section{Referee Bias}

There is now overwhelming evidence that referee decisions favor the home team. This was first suggested by analyzing the frequency of disciplinary cards and other referee decisions [9,22-26]. The bias was then demonstrated in a laboratory setting $[27,28]$ and subsequently by returning to referee decisions after carefully controlling for confounding variables [10,29-32]. However, caution in the interpretation of some of these results has been suggested [33]. The reason for apparent referee bias is thought to be a consequence of crowd support, but this has not yet been established, neither has whether the bias acts primarily on the home team, the 
away team, or both. An interesting study involving the ethnicity of the referee and of the competing teams also pointed to unequal treatment by the referee, suggesting that other factors might be at work [34].

\section{Territoriality}

Humans and animals are known to respond to a real or perceived invasion of their home territory and it seems reasonable to suppose this might be a factor in home advantage. The idea that this might be at work in football was originally put forward by Morris [1]. Evidence was later produced showing that home players experience an increase in hormone activity before a game [35-38]. Subsequently it has been shown that teams playing in countries, or specific cities or regions within countries, often isolated and with a history of conflict, have increased home advantage perhaps due to a heightened sense of territoriality $[14,17]$.

\section{Special Tactics}

Home and away teams may approach games differently from a tactical viewpoint. If the away team were to use a more caution and defensive approach this might be expected to hand a territorial and psychological advantage to the home team $[3,5]$. Although a study documenting increased home advantage in the second leg of European cup games suggested, among other things, tactical considerations as an explanation [39], there is still no firm evidence to link tactics with home advantage. Clear differences between home and away teams in terms of match performance indicators have been shown, with implications on tactical strategies $[18,40,41]$.

\section{Rule Factors}

Although football is a simple game, the last two decades have seen important changes in the rules of the game as well as the regulations involving player participation, all of which have the potential to affect home advantage. Changing from two to three points for a win has produced conflicting findings in relation to home advantage $[2,3,8,42,43]$. The increased use of substitutes and the lengthening of the halftime interval have also been hypothesized as having an effect due to a greater degree of what has been termed information transfer' [44]. The rule limiting passing back to the goalkeeper is another possibility, as is the directive to referees to punish tackles from behind more severely. The Bosman ruling of 1995 making it easier for players to move internationally and more frequently from club to club has resulted in teams, especially in England, consisting mainly of nonnative born players. This is likely to dilute the relationship between the players and their 'home' city and home fans, and hence has the potential to influence home advantage.

\section{Psychological Factors}

Since players and coaches are well aware of the existence of home advantage, their mental attitude before and during a game is certainly going to be affected. One possibility is that although there may be real reasons for the advantage, these are being augmented by the beliefs of the players and those around them. Hence a self perpetuating phenomenon is being established $[3,4,5]$. A review of home advantage in football from a psychological and physiological viewpoint has been made by Neave and Wolfson [38]. Ultimately it is what goes on in the mind of players, coaches and referees that determine their actions and hence the result of a game and the role played by home advantage. A study of five players appears to be the only investigation into the psychological state of footballers in relation to home advantage [45]. Two papers have focused on how players might become better prepared to cope with the perceived disadvantage of playing away from home $[36,46]$.

\section{Interaction of Causes}

One of the problems about researching home advantage in football is the fact that the likely causes outlined above will be operating together, each interacting with the other in ways that will be difficult to investigate, isolate and quantify. A model for these interactions has been proposed [4,5]. Thus a researcher will need to develop a strategy which either takes a multivariate approach, or which carefully controls for possible confounding variables that are not the main focus of the study.

\section{Other Considerations}

Although there are different ways of quantifying home advantage, team ability has been recognized as a factor that affects the magnitude of home advantage and needs to be taken into account, especially if individual teams are being compared. Several different approaches have been used $[12,16,19,32,47]$. In addition, the general recent decline in home advantage and the significant long-term fluctuations need to be incorporated into the analysis when basing a study on more than a few years of data $[5,8,39,41,42,48]$. Large differences in home advantage between countries must also be considered as a confounding variable, as well as having the potential to throw light on possible causes $[14,17,49]$. It has been suggested that game importance might also be a factor to consider [39]. Since football's world governing body (FIFA) is now making use of its world football rankings to seed teams in World Cup qualification, it is worth noting that home advantage is totally ignored in the procedure to calculate the rankings [50]. This is an astonishing omission given the importance that home advantage is known to have in determining the result of a game.

In conclusion, the exact same words written at the end of my paper on home advantage in football in 1986 are just as relevant over 20 years later: "Clearly, there is still much to be learnt about the complex mechanisms that cause home advantage, both in soccer and other sports. The topic remains a fruitful area of research for sports historians, sociologists, psychologists and statisticians alike" [3].

\section{REFERENCES}

[1] Morris D. The Soccer Tribe. London: Cape 1981.

[2] Dowie J. Why Spain Should Win the World Cup. New Sci 1982; 94: 693-95.

[3] Pollard R. Home advantage in soccer: a retrospective analysis. J Sports Sci 1986; 4: 237-48.

[4] Pollard R, Pollard G. Venteja de ser el equipo local en fútbol: una reseña de su existencia y causas. Rev Int Fútbol Ciencia 2005; 3: 31-44.

[5] Pollard R. Home advantage in soccer: variations in its magnitude and a literature review of the inter-related factors associated with its existence. J Sport Behav 2006; 29: 169-89.

[6] Wolfson S, Wakelin D, Lewis M. Football supporters' perceptions of their role in the home advantage. J Sports Sci 2005; 23: 365-74. 
[7] Lewis M, Goltsi V. Perceptions of contributions to the home advantage by English and Greek football fans. In: Theodorakis Y, Goudas M, Papaioannou A, Eds. Book of long papers, 12th European Congress of Sport Psychology; 2007: Halkidiki, Greece: FEPSAC 2007; pp. 61-64.

[8] Pollard R, Pollard G. Long-term trends in home advantage in professional team sports in North America and England (1876-2003). J Sports Sci 2005; 23: 337-50.

[9] Nevill AM, Newell SM, Gale S. Factors associated with home advantage in English and Scottish soccer matches. J Sports Sci 1996; 14: 181-86.

[10] Boyko RH, Boyko AR, Boyko MG. Referee bias contributes to home advantage in English Premiership football. J Sports Sci 2007; 25: 1185-94.

[11] Heuer A, Rubner O. Fitness, chance and myths: an objective view on soccer results. arXiv:0803.0614v2 [physics.data-an]. 2008 March 7; [cited 2008 April 20]. Available from http://arxiv.org/abs/0803.0614.

[12] Clarke SR, Norman JM. Home ground advantage of individual clubs in English soccer. Statistician 1995; 44: 509-21.

[13] Brown TD, Van Raalte JL, Brewer BW, Winter CR, Cornelius AE, Andersen MB. World Cup soccer home advantage. J Sport Behav 2002; 25: 134-44.

[14] Pollard R. Worldwide regional variations in home advantage in association football. J Sports Sci 2006; 24: 231-240.

[15] Goddard J. Who wins the football? Significance 2006; 3(1): 16-19.

[16] Pollard R, da Silva CD, Nísio CM. Home advantage in football in Brazil: differences between teams and the effects of distance traveled. Braz J Soccer Sci 2008; Forthcoming.

[17] Pollard R, Seckin A. Why is home advantage in South-east Europe the highest in the world? In: Theodorakis Y, Goudas M, Papaioannou A, Eds. Book of long papers, 12th European Congress of Sport Psychology; 2007: Halkidiki, Greece: FEPSAC 2007; pp. 53-56.

[18] Seckin A, Pollard R. Home advantage in Turkish professional soccer. J Sports Sci Med 2007; Suppl.10: 203-04.

[19] Barnett V, Hilditch S. The effect of an artificial pitch surface on home team performance in football (soccer). J R Statist Soc A 1993; 156: 39-50.

[20] Dosseville FEM. Influence of ball type on home advantage in French professional soccer. Percept Mot Skills 2007; 104: 347-51.

[21] McSharry PE. Altitude and athletic performance: statistical analysis using football results. BMJ 2007; 335: 1278-81.

[22] Glamser FD. Contest location, player misconduct, and race: a case from English soccer. J Sport Behav 1990; 13: 41-49.

[23] Lefebvre LM, Passer MW. The effects of game location and importance on aggression in team sport. Int J Sport Psych 1974; 5: 10210.

[24] Garciano L, Palacios-Huerta I, Prendergast C. Favoritism under social pressure. Working Paper 8376. Cambridge: National Bureau of Economic Research 2001.

[25] Thomas S, Reeves C, Smith A. English soccer teams' aggressive behavior when playing away from home. Percept Mot Skills 2006; 102: 317-20.

[26] Poulter DM. Non-outcome measures underlying the home advantage effect for teams and individual players in the UEFA Champions League. In: Theodorakis Y, Goudas M, Papaioannou A, Eds. Book of long papers, 12th European Congress of Sport Psychology; 2007: Halkidiki, Greece: FEPSAC 2007; pp. 49-52.

[27] Nevill A, Balmer N, Williams M. Crowd influence on decisions in association football. Lancet 1999; 353: 1416.

[28] Nevill AM, Balmer NJ, Williams AM. The influence of crowd noise and experience upon refereeing decisions in football. Psychol Sport Exerc 2002; 3: 261-72.
[29] Sutter M, Kocher MG. Favoritism of agents - The case of referees home bias. J Econ Psychol 2004; 25: 461-69.

[30] Dohmen TJ. Social pressure influences decisions of individuals: evidence from the behavior of football referees. Discussion Paper No. 1595. Bonn: IZA 2005.

[31] Buraimo B, Forrest D, Simmons R. The twelfth man? Refereeing bias in English and German soccer. Working Paper Series, Paper No. 07-07. Limoges, France: International Association of Sports Economists 2007.

[32] Dawson P, Dobson S, Goddard J, Wilson J. Are football referees really biased and inconsistent?: evidence on the incidence of disciplinary sanction in the English Premier League. J R Statist Soc A 2007; 170: 231-50.

[33] Johnston R. On referee bias, crowd size, and home advantage in the English soccer Premiership. J Sports Sci 2008; 26: 563-68.

[34] Messner C, Schmid B. Über die Schwierigkeit, unparteiische Entscheidungen zu fällen. Z Sozialpsychol 2007; 38: 105-10.

[35] Neave N, Wolfson S. Testosterone, territoriality, and the 'home advantage'. Physiol Behav 2003; 78: 269-75.

[36] Wolfson S, Neave N. Preparing for home and away matches. Insight 2004; 8(2): 43-46.

[37] Wolfson S, Neave N, Anderson M. Hormones and the home advantage in English football. In: Theodorakis Y, Goudas M, Papaioannou A, Eds. Book of long papers, 12th European Congress of Sport Psychology; 2007: Halkidiki, Greece: FEPSAC 2007; pp. 57-60.

[38] Neave N, Wolfson S. The home advantage: psychological and physiological factors in soccer. In: Lavalle D, Thatcher J, Jones MV, Eds. Coping and Emotion in Sport. New York, Nova Science Publishers 2004; 127-44.

[39] Page L, Page K. The second leg home advantage: evidence from European football cup competitions. J Sports Sci 2007; 25: 154756.

[40] Carmichael F, Thomas D. Home-field effect and team performance. J Sports Econ 2005; 6: 264-81.

[41] Tucker W, Mellalieu SD, James N, Taylor JB. Game location effects in professional soccer: a case study. Int J Perform Anal Sport 2005; 5(2): 23-35.

[42] Thomas S, Reeves C, Davies S. An analysis of home advantage in the English football premiership. Percept Mot Skills 2004; 99: 1212-16.

[43] Jacklin PB. Temporal changes in home advantage in English football since the Second World War: what explains improved away performance? J Sports Sci 2005; 23: 669-79.

[44] Tsonis AA, Tsonis PA. Information transfer and home field advantage. Math Today 2001; 37: 24-25.

[45] Waters A, Lovell G. An examination of the homefield advantage in a professional English soccer team from a psychological standpoint. Football Studies 2002; 5: 46-59.

[46] Pollard R. Away disadvantage: five steps for coping. Insight Live 2006; 19.

[47] Bray SR, Law J, Foyle, J. Team quality and game location effects in English professional soccer. J Sport Behav 2003; 26: 319-34.

[48] Konig RH. Balance in competition in Dutch soccer. Statistician 2000; 49: 419-31.

[49] Da Silva CD, Moreira DG. A vantagem em casa no futebol: comparação entre o Campeonato Brasileiro e as principais ligas nacionais do mundo. Rev Bras Cineantropom Desempenho Hum 2008; 10: $184-88$

[50] FIFA/Coca-Cola World Ranking Procedure [cited 2008 April 20]. Available from http://www.fifa.com/worldfootball/ranking/procedure/men.htm 